\title{
The Impact of Gender Differences on Healthy Lifestyle and its Subscales Among Patients With Coronary Artery Disease
}

\author{
Amir Maleki, ${ }^{1}$ Majid Haghjoo, ${ }^{2}$ and Mehdi Ghaderi ${ }^{1,}$ \\ ${ }^{1}$ Department of Social Sciences, Payame Noor University, Tehran, IR Iran \\ ${ }^{2}$ Cardiac Electrophysiology Research Center, Rajaie Cardiovascular Medical and Research Center, Iran University of Medical Sciences, Tehran, IR Iran \\ "Corresponding author: Mehdi Ghaderi, Department of Social Science, Payame Noor University, Tehran, IR Iran, E-mail: M_Ghaderi@pnu.ac.ir
}

Received 2015 September 12; Revised 2015 December 14; Accepted 2016 January 02.

\begin{abstract}
Background: Coronary artery disease (CAD) is one of the major causes of death and disability all over the world. The increasing prevalence of CAD as well as its high economic cost makes it a serious health problem in Iran.

Objectives: The study aimed to evaluate the impact of gender differences on healthy lifestyle measures among patients with CAD. Patients and Methods: In this descriptive cross-sectional study, 412 patients with CAD (239 men and 173 women) were selected between January 2015 and June 2015. Data were collected by demographic characteristic forms and a healthy lifestyle questionnaire. The data were analyzed using SPSS software with appropriate statistical tests.

Results: There was no significant difference in age, blood pressure, and cholesterol between the two genders $(\mathrm{P}=0.573, \mathrm{P}=0.092$, $\mathrm{P}=0.438)$. Men were more educated than women $(\mathrm{P}=0.000)$, and had higher levels of low-density lipoprotein and high-density lipoprotein $(\mathrm{P}=0.000)$. The mean of healthy lifestyle scores was $19.2 \pm 4.2$ for the men and $18.8 \pm 3.2$ for the women. Overall, there was no significant difference between two genders in healthy lifestyle scores $(\mathrm{P}=0.342)$. However, among the healthy lifestyle subscales, women had healthier nutrition $(\mathrm{P}=0.000)$ and were less inclined to smoke and drink than men $(\mathrm{P}=0.000)$. Men had more physical activity $(\mathrm{P}=0.000)$, more health responsibility $(\mathrm{P}=0.000)$, and more health-based purchases $(\mathrm{P}=0.000)$. There was no significant difference between the two genders in stress management $(\mathrm{P}=0.272)$.

Conclusions: The results indicated that the patients' lifestyles were unhealthy overall. However, tendency towards healthy behaviors was different between men and women. Therefore, it is important and necessary to emphasize gender differences in prevention and health promotion programs.
\end{abstract}

Keywords: Coronary Artery Disease, Healthy Lifestyle, Gender

\section{Background}

Cardiovascular disease (CVD) is one of the reasons for the death of individuals all over the world, and contributes to nearly one third of all global deaths. By 2020 approximately 25 million deaths annually are expected from CVD, and almost half of those deaths will be related to coronary artery disease (CAD) (1). The spread of CAD and its risk factors in Iran is very high compared with Western countries, but it is similar to some other Middle Eastern countries. Recent data prove that CAD risk factors are prevalent among Iranian adult populations (2).

The majority of CAD is caused by risk factors that can be controlled, treated, or modified. Among modifiable lifestyle factors, smoking (3), excessive drinking $(4,5)$, obesity $(6,7)$, and physical activity $(8,9)$ are generally accepted behaviors that are considered to be related to an increased risk of chronic diseases such as cancer and cardiovascular diseases. Moreover, increased low-density lipoprotein and decreased high-density lipoprotein are both risk factors of coronary artery disease (10). These factors can be reduced by modifying one's environment and changing one's behavior or lifestyle. Individual healthy lifestyles may be affected by structural factors (e.g., gender, socioeconomic status, socio-cultural resources, and health policies). Even though all these factors are of great importance, gender has a more significant influence. In gender research, the term "gender" is employed to make a distinction between biological sex and the social, cultural, and historical construction of femininities and masculinities (11). Gender influences the way one is viewed and evaluated by other people. An individual's gender also affects the way a person evaluates others. Recent research has shown gender influences on our perception of healthy and unhealthy lifestyles (12), and there are also gender differences in making health-related decisions (4). The latest studies have found crucial differences between males and females in their profile of a health-promoting lifestyle: in physical 
activity, interpersonal relations, and stress management, men had more positive results compared with women (13). On the contrary, women drink less, have fewer sexual partners, and use birth control and seat belts more often than men do (14). Gender differences in healthy behavior are also affected by the interacting effects of fundamental aspects of traditional gender roles and the contemporary context (15). The rifeness and morbidity related to CAD is one of the major health problems in Iran (2). Although CAD is a major reason for death, ailment, and disability, contributing to the high cost of health care in Iran (16), and although a change in lifestyle is the most advantageous way to reduce the risk of CAD (17), there have been few studies evaluating gender and healthy lifestyles among patients. Therefore, research in this area is necessary and important.

\section{Objectives}

The aim of this study was to evaluate the impact of gender differences on a healthy lifestyle and its subscales among patients with CAD.

\section{Patients and Methods}

412 patients with CAD, including 239 men and 173 women, participated in this cross-sectional study between January 2015 and June 2015 at Rajaie cardiovascular medical and research center. The samples were selected from four different wards: men's internal, women's internal, Diplomat, and VIP.

In this research, the convenience sampling method was used, and the study sample size was calculated using the following formula (Equation 1):

$n=\frac{\left(z_{1-\frac{\alpha}{2}}\right)^{2} \times p(1-p)}{d^{2}}$

Here, $Z_{1-\alpha / 2}=1.96 ; P=0.5$, where $\mathrm{p}$ means the existence of the trait (i.e. healthy lifestyle); and $d=0.05$. Therefore, the sample size was calculated as 385 . To eliminate the effect of missing data, after adding 27 samples, a final sample size of 412 was considered for this study.

To address potential sources of bias, proper research tools were used, accurate and reliable texts were studied, and trained interviewers were employed. Potential confounders in this research are education, ethnicity, and socio-economic conditions, which were controlled for by the logistic regression method.

Data were collected by a demographic characteristic form and a healthy lifestyle questionnaire. To measure healthy lifestyle, based on the theoretical literature and existing scales (i.e., HPLPII) a relevant scale was constructed which included 44 questions related to six subscales: nutrition (12 items), stress management (7 items), avoiding tobacco and alcohol (6 items), physical activity (7 items), health responsibility (8 items), and health-based purchases ( 4 items), all of which were measured based on a four-point Likert scale $(1=$ never, $2=$ sometimes, $3=$ often, and $4=$ routinely). The scores on this lifestyle scale ranged from 5 to 30. The higher the scores, the healthier the lifestyles.

A literature review and content experts' evaluation confirmed the content validity. Factor analysis that confirmed a six-dimensional structure of the healthy lifestyle questionnaire supported the construct's validity. The Alpha coefficient of internal consistency for the total scale was 0.914; Alpha coefficients for the subscales ranged from 0.805 to 0.917 (Table 1 ). The collected data were analyzed using SPSS v.18.0 statistical software (SPSS Inc. Chicago, IL, USA). We tested all interval data for normal distribution, with one sample Kolmogorov-Smirnov test. Mean values of continuous parameters were compared between the two groups using an independent samples t-test. P values $\leq$ 0.05 were considered statistically significant in this study.

Table 1. Cronbach's Alpha Coefficients of Healthy Lifestyle Scale and Subscales

\begin{tabular}{lc}
\hline Scale and Subscales & Cronbach's Alpha Coefficients \\
\hline Nutrition & 0.879 \\
\hline Stress Management & 0.876 \\
\hline Abstaining from Tobacco and Alcohol & 0.805 \\
\hline Physical Activity & 0.930 \\
\hline Health Responsibility & 0.916 \\
\hline Health-based Purchases & 0.919 \\
\hline Total Scale & 0.914 \\
\hline
\end{tabular}

\section{Results}

General characteristics of the study participants are shown in Table 2. Of the 412 studied patients, 239 (58\%) were men and 173 (42\%) were women. The mean age was $61 \pm 7.39$ years for the men and $60.6 \pm 6.71$ years for the women. There was no significant difference in age between the two gender groups $(\mathrm{P}=0.573)$. The mean number of years of education was $10.5 \pm 4.87$ for the men and $5 \pm 4.83$ for the women. Thus the men were significantly more educated than women $(\mathrm{P}=0.000)$. Among the clinical parameters, the means of blood pressure and total cholesterol were similar between the two genders. The means of highdensity lipoprotein were higher in the men compared to 
the women, whereas the means of low-density lipoprotein were higher in the women.

As Table 3 demonstrates, the analysis of CAD patients' healthy lifestyle scores indicated that the mean of healthy lifestyle scores was $19.2 \pm 4.2$ for the men and $18.8 \pm 3.2$ for the women. Overall, the relationship between gender and healthy lifestyle was not significant $(\mathrm{P}=0.342)$. Nevertheless, there were significant differences between the two genders in healthy lifestyle sub-scales. Among these, the means of nutrition and avoiding tobacco and alcohol were higher in the women compared to the men. However, the means of physical activity, health responsibility, and health-based purchases were higher in the men compared to the women. The differences between the two genders were statistically significant in these four subscales (all P $=0.000)$. On the other hand, the means of stress management were similar between both genders. The test finding for the relation between gender and stress management was not significant $(\mathrm{P}=0.272)$.

\section{Discussion}

The results indicated that the patients with coronary artery disease scored below average on the healthy lifestyle scale. Overall, these men and women had unhealthy lifestyles. Though there was no significant difference in total healthy lifestyle scores between the two genders, there were differences between them on the healthy lifestyle sub-scales.

Numerous studies have shown that women adopt healthier habits concerning eating, exercising, and drinking; on average, men are more overweight and less concerned about health and nutrition than women are $(12,16)$. Related research indicates that since women are more often the end users of health services and health information, they are more cautious and informed about health (18). According to studies performed in modern western societies there are consistent associations between gender and specific foods: meat (especially red meat), alcohol, and hearty portion sizes are associated with masculinity, while vegetables, fruit, fish, and cultured dairy products (e.g., yogurt, cottage cheese) are associated with femininity (19, 20). Regarding eating habits, several studies confirm that women are usually more cautious about diet and healthdiet relationship implications, and are also more willing to change their dietary habits than men. The results of this study revealed differences between the two genders in nutrition, such that women had significantly healthier nutrition and dietary patterns than men.

Stress has also been recognized as a public health problem. Growing evidence demonstrates that various situations stress out both men and women. It is more likely for males to list finances and work-related events as sources of their stress (stressors). On the other hand, females list family and health-related events as stressors more than males do (21). In a meta-analytic review of gender differences in control of stress (22), the findings indicated that females use social support and help-seeking behaviors to alleviate stress, to protect themselves against depression and anxiety disorders $(23,24)$. In contrast, "men used more maladaptive coping strategies, drank more alcohol and ate less healthy food but exercised more than women" (25). Stress management leads to reduction in health risks and is one of the most important factors in individual health promotion. Our findings showed that there was no significant difference between men and women in stress management. Nevertheless, both genders had moderate mechanisms for controlling stress.

Regular physical activity is an important contributor to good health. Physical activity leads to a large decrease in risk factors for coronary heart disease by reducing blood pressure in people with hypertension, improving blood lipid profiles, and improving insulin sensitivity (26). Prevailing trends such as urbanization, modernization, and changes in occupational behaviors have resulted in dietary changes and therefore declines in physical activity (27). Patterns of physical activity are different among males and females and across age groups and societies. Other studies showed that men are more active than women in leisuretime, though not all the results were consistent $(28,29)$. According to more recent data, considering all domains of activity practice, no gender differences were observed (30). Our results confirmed the finding of previous studies. The level of physical activity among both genders was less than the average; the women had significantly lower level physical activity levels than the men.

Because of the related smoking pattern, personality traits, and endorsement of hegemonic ideals, smoking "one of the most risky health behaviors" is considered a masculine phenomenon. Men start smoking earlier than women, smoke more cigarettes per day, inhale more deeply, and consume further tobacco products like pipes, cigars, or smokeless tobacco (31). Extroversion, rebelliousness, antisocial tendencies, risk taking, and social deviance are personality traits that have a direct relationship with the occurrence of smoking behavior, and are more common among men than women $(32,33)$. Waldron (34) identifies three main reasons for gender differences in smoking behavior: "First, general characteristics of traditional sex roles, including men's greater social power and generally greater restrictions on women's behavior, contributed to widespread social pressures against women's smoking. Second, traditional sex role norms and expectations have fostered gender differences in personal characteristics and 
Table 2. Demographic and Clinical Characteristics by Gender ${ }^{a}$

\begin{tabular}{|c|c|c|c|}
\hline Parameters & Males $(n=239)$ & Females $(n=173)$ & P Value \\
\hline Age, $y$ & $61 \pm 7.39$ & $60.6 \pm 6.71$ & 0.573 \\
\hline Years of Education & $10.5 \pm 4.87$ & $5 \pm 4.83$ & 0.000 \\
\hline Blood Pressure & $12.6 \pm 1.43$ & $12.8 \pm 1.34$ & 0.092 \\
\hline Cholesterol, mg/dL & $178.1 \pm 28.54$ & $180.2 \pm 26.72$ & 0.438 \\
\hline LDL, $\mathbf{m g} / \mathbf{d L}$ & $89.67 \pm 22.05$ & $104.1 \pm 20.06$ & 0.000 \\
\hline HDL, mg/dL & $37.52 \pm 5.44$ & $35.17 \pm 4.35$ & 0.000 \\
\hline
\end{tabular}

Abbreviations: BMI, body mass index; CAD, coronary artery disease; HDL, high-density lipoprotein; LDL, low-density lipoprotein.

${ }^{\mathrm{a}}$ Data are presented as mean $\pm \mathrm{SD}$.

Table 3. Healthy Lifestyle and its Subscales in Patients with Coronary Artery Disease $\mathrm{e}^{\mathrm{a}, \mathrm{b}}$

\begin{tabular}{|c|c|c|c|c|}
\hline Healthy Lifestyle and its Subscales/Range & Males $(\mathbf{n}=\mathbf{2 3 9})$ & Females $(n=173)$ & Total $(n=412)$ & PValue \\
\hline Nutrition & & & & 0.000 \\
\hline $12-48$ & $28.1 \pm 3.6$ & $30.7 \pm 2.6$ & $29.2 \pm 3.4$ & \\
\hline Stress Management & & & & 0.272 \\
\hline $7-28$ & $17.2 \pm 3.1$ & $16.8 \pm 2.6$ & $17 \pm 2.9$ & \\
\hline Avoiding tobacco and alcohol & & & & 0.000 \\
\hline $6-24$ & $20.4 \pm 3$ & $22.5 \pm 0.63$ & $21.2 \pm 2.5$ & \\
\hline Physical activity & & & & 0.000 \\
\hline $7-28$ & $14.1 \pm 5$ & $9.7 \pm 4$ & $13 \pm 4.3$ & \\
\hline Health responsibility range & & & & 0.000 \\
\hline $8-32$ & $22.2 \pm 5$ & $20.7 \pm 4.7$ & $21.5 \pm 4.8$ & \\
\hline Health-based purchase & & & & 0.000 \\
\hline $4-16$ & $12.9 \pm 2.6$ & $10.9 \pm 3.2$ & $11.7 \pm 2.9$ & \\
\hline Healthy lifestyle & & & & 0.342 \\
\hline $5-30$ & $19.2 \pm 4.2$ & $18.8 \pm 3.2$ & $19 \pm 3.8$ & \\
\hline
\end{tabular}

${ }^{\text {a }}$ P value $<0.05$

${ }^{\mathrm{b}}$ Values are expressed as mean $\pm \mathrm{SD}$.

experiences which influence smoking adoption. For example, rebelliousness has been more expected and accepted for males, and greater rebelliousness among adolescent males has contributed to greater smoking adoption by males. Finally, certain aspects of sex roles have contributed to gender differences in appraisal of the costs and benefits of smoking. For example, physical attractiveness is emphasized more for females and the contemporary beauty ideal is very slender, so females are more likely to view weight control as a benefit of smoking". The findings of this study demonstrated that respondents of both genders had little desire for smoking and drinking. However, women were less inclined to smoking and drinking than men were, and this finding confirmed the results of previous research.
Regarding gender, generally men are often reluctant and have no tendency to gather health-related information, both in times of stressful life events and in everyday life (34). Based on these observations, because of gender role strains and social constructions of masculinity, men are unaware of sources of health-related information and don't have enough competencies to search for them because they are either ignorant or reluctant. Hence they have little motivation for seeking out what they know to be available (35). Research, both prior to the internet (36) and since the Internet appeared (37) that has focused on gender as a variable in health information seeking behavior demonstrates that females search for health-related information more actively than males. In this research, men 
had more health responsibility than women. This finding does not support previous research. The lower level of education among women in this study (Table 2) suggests that they are more likely to ignore health responsibility and refuse to comply with a healthy lifestyle.

Finally, health-based purchases - buying from high quality stores, buying high quality cosmetic and hygienic goods, consuming healthy food, etc. is one of the important factors in individuals' health promotion. The findings of this research indicated that the CAD patients were more likely than average people to make health-based purchases, more so among the men than the women.

To sum up, the results of this study showed that the patients' lifestyles were unhealthy. However, there were substantial differences in healthy lifestyle subscales between the two genders. The men had significantly more physical activity, more health responsibility, and made more health-based purchases. Conversely, women had healthier nutrition and were less inclined to smoking and drinking. There was no difference between both genders only in stress management. These results suggest that gender has played a key role in explaining health inequalities. Therefore, it is important and necessary to emphasize gender differences in prevention and health promotion programs.

\subsection{Limitations}

Although this research has been prepared carefully, there were some unavoidable limitations. First, because of the time limit, this research was conducted only on a small group of participants at only one hospital. Therefore, to generalize the results for larger groups, future studies should involve more participants at different hospitals to cover the whole society. Another limitation was the lack of a standardized questionnaire on the purpose of the study. Finally, comparing healthy lifestyles between patients and non-patients, along with a combination of quantitative and qualitative methods, could better analyze and explain the results.

\section{Acknowledgments}

The authors deeply appreciate all the staff of the four different wards (the men's and women's internal wards, the Diplomat ward, and the VIP ward) at Rajaie cardiovascular medical and research center for their help and assistance during this research. Also, we would like to thank Shirin Ahmadnia and Hooman Bakhshandeh for all their generosity in giving us help and guidance.

\section{References}

1. Batic-Mujanovic O, Gavran L, Hasanagic M, Cerni E. Gender differences in lifestyle components among patients with coronary heart disease. Acta Medica Academica. 2008;37(2):79-85.
2. Ebrahimi M, Kazemi-Bajestani SM, Ghayour-Mobarhan M, Ferns GA. Coronary artery disease and its risk factors status in iran: a review. Iran Red Crescent Med J. 2011;13(9):610-23. [PubMed: 24069531].

3. Nolen-Hoeksema S, Hilt L. Possible contributors to the gender differences in alcohol use and problems. J Gen Psychol. 2006;133(4):357-74. doi: 10.3200/GENP.133.4.357-374. [PubMed: 17128956].

4. Dawson DA. Alcohol consumption, alcohol dependence, and all-cause mortality. Alcohol Clin Exp Res. 2000;24(1):72-81. [PubMed:10656196].

5. Lin Y, Kikuchi S, Tamakoshi A, Wakai K, Kawamura T, Iso H, et al. Alcohol consumption and mortality among middle-aged and elderly Japanese men and women. Ann Epidemiol. 2005;15(8):590-7. doi: 10.1016/j.annepidem.2004.10.010. [PubMed:16118003].

6. Hozawa A, Okamura T, Oki I, Murakami Y, Kadowaki T, Nakamura K, et al. Relationship between BMI and all-cause mortality in Japan: NIPPON DATA80. Obesity (Silver Spring). 2008;16(7):1714-7. doi: 10.1038/oby.2008.237. [PubMed: 18421264].

7. Tsugane S, Sasaki S, Tsubono Y. Under- and overweight impact on mortality among middle-aged Japanese men and women: a 10-y follow-up of JPHC study cohort I. Int J Obes Relat Metab Disord. 2002;26(4):529-37. [PubMed: 12075580].

8. Fujita K, Takahashi H, Miura C, Ohkubo T, Sato Y, Ugajin T, et al. Walking and mortality in Japan: the Miyagi Cohort Study. J Epidemiol. 2004;14 Suppl 1:S26-32. [PubMed: 15143875].

9. Hamer M, Chida Y. Walking and primary prevention: a meta-analysis of prospective cohort studies. Br J Sports Med. 2008;42(4):238-43. doi: 10.1136/bjsm.2007.039974. [PubMed: 18048441].

10. Assari S, Ahmadi K, Kazemi Saleh D. Gender Differences in the Association between Lipid Profile and Sexual Function among Patients with Coronary Artery Disease. Int Cardiovasc Res J. 2014;8(1):9-14. [PubMed: 24757645].

11. Rubin G. In: Toward an Anthropology of Women. Reiter R, editor. New York: Monthly Review Press; 1975 . Traffic in Women.

12. von Bothmer MI, Fridlund B. Gender differences in health habits and in motivation for a healthy lifestyle among Swedish university students. Nurs Health Sci. 2005;7(2):107-18. doi: 10.1111/j.14422018.2005.00227.x. [PubMed: 15877687].

13. Al-Kandari F, Vidal VL. Correlation of the health-promoting lifestyle, enrollment level, and academic performance of College of Nursing students in Kuwait. Nurs Health Sci. 2007;9(2):112-9. doi: 10.1111/j.14422018.2007.00311.x. [PubMed: 17470185].

14. Henson JM, Carey MP, Carey KB, Maisto SA. Associations among health behaviors and time perspective in young adults: model testing with boot-strapping replication. J Behav Med. 2006;29(2):127-37. doi: 10.1007/s10865-005-9027-2. [PubMed: 16421652].

15. Waldron I. Trends in gender differences in mortality: Relationships to changing gender differences in behavior and other causal factors. In: Anandale E, Hunt K, editors. Gender Inequalities in Health. Buckingham: Open University Press; 2000. pp. 150-81.

16. Hatmi ZN, Tahvildari S, Gafarzadeh Motlag A, Sabouri Kashani A Prevalence of coronary artery disease risk factors in Iran: a population based survey. BMC Cardiovasc Disord. 2007;7:32. doi: 10.1186/14712261-7-32. [PubMed: 17971195].

17. Najafi M, Sheikhvatan M. Gender differences in coronary artery disease: correlational study on dietary pattern and known cardiovascular risk factors. Int Cardiovasc Res J. 2013;7(4):124-9. [PubMed: 24757636].

18. Idler EL. Discussion: gender differences in self-rated health, in mortality, and in the relationship between the two. Gerontol. 2003;43(3):3725.

19. O’Doherty Jensen K, Holm L. Preferences, quantities and concerns: socio-cultural perspectives on the gendered consumption of foods. Eur J Clin Nutr. 1999;53(5):351-9. [PubMed: 10369489]. 
20. Sobal J. Men, meat, and marriage: Models of masculinity. Food Foodways. 2005;13(1-2):135-58.

21. McDonough P, Walters V. Gender and health: reassessing patterns and explanations. Soc Sci Med. 2001;52(4):547-59. [PubMed: 11206652].

22. Tamres LK, Janicki D, Helgeson VS. Sex differences in coping behavior: A meta-analytic review and an examination of relative coping.Pers Soc Psychol Rev. 2002;6(1):2-30.

23. Plaisier I, de Bruijn JG, de Graaf R, ten Have M, Beekman AT, Penninx BW. The contribution of working conditions and social support to the onset of depressive and anxiety disorders among male and female employees. Soc Sci Med. 2007;64(2):401-10. doi: 10.1016/j.socscimed.2006.09.008. [PubMed:17055138].

24. Torkelson E, Muhonen T. The role of gender and job level in coping with occupational stress. Work Stress. 2004;18(3):267-74.

25. Lindquist TL, Beilin LJ, Knuiman MW. Influence of lifestyle, coping, and job stress on blood pressure in men and women. Hypertension. 1997;29(1 Pt 1):1-7. [PubMed: 9039072].

26. Pate RR, Pratt M, Blair SN, Haskell WL, Macera CA, Bouchard C, et al. Physical activity and public health. A recommendation from the Centers for Disease Control and Prevention and the American College of Sports Medicine. JAMA. 1995;273(5):402-7. [PubMed: 7823386].

27. Nugent R. Chronic diseases in developing countries: health and economic burdens. Ann N Y Acad Sci. 2008;1136:70-9. doi: 10.1196/annals.1425.027. [PubMed: 18579877].

28. Monteiro CA, Conde WL, Matsudo SM, Matsudo VR, Bonsenor IM, Lotufo PA. A descriptive epidemiology of leisure-time physical activity in Brazil, 1996-1997. Rev Panam Salud Publica. 2003;14(4):246-54. [PubMed: 14662075].
29. Steptoe A, Wardle J, Cui W, Bellisle F, Zotti AM, Baranyai R, et al. Trends in smoking, diet, physical exercise, and attitudes toward health in European university students from 13 countries, 1990-2000. Prev Med 2002;35(2):97-104. [PubMed:12200093].

30. Hallal PC, Victora CG, Wells JC, Lima RC. Physical inactivity: prevalence and associated variables in Brazilian adults. Med Sci Sports Exerc. 2003;35(11):1894-900. doi: 10.1249/01.MSS.0000093615.33774.0E. [PubMed: 14600556].

31. Waldron I. Patterns and causes of gender differences in smoking. Soc Sci Med. 1991;32(9):989-1005. [PubMed: 2047903].

32. Grunberg NE, Winders SE, Wewers ME. Gender differences in tobacco use. Health Psychol. 1991;10(2):143-53. [PubMed: 2055212].

33. Waldron I. Women, work, and health. Springer; 1991. pp. 17-38.Effects of labor force participation on sex differences in mortality and morbidity.

34. Mansfield AK, Addis ME, Mahalik JR. "Why won't he go to the doctor?": The psychology of men's help seeking. Int J Men's Health. 2003;2(2):93.

35. Courtenay WH. Constructions of masculinity and their influence on men's well-being: a theory of gender and health. Soc Sci Med. 2000;50(10):1385-401. [PubMed: 10741575].

36. Rakowski W, Assaf AR, Lefebvre RC, Lasater TM, Niknian M, Carleton RA. Information-seeking about health in a community sample of adults: correlates and associations with other health-related practices. Health Educ Q. 1990;17(4):379-93. [PubMed: 2262319].

37. Renahy E, Chauvin P. Internet uses for health information seeking A literature review. Rev Epidemiol Sante Publique. 2006;54(3):263-75. [PubMed: 16902386]. 